\title{
Introducing Collaborative Practices to Undergraduate Studies
}

\author{
Jaana Holvikivi $^{1(\sqrt{(})}$, Minna Lakkala ${ }^{2}$, and Hanni Muukkonen ${ }^{2}$ \\ ${ }^{1}$ Helsinki Metropolia University of Applied Sciences, Helsinki, Finland \\ jaana.holvikivi@metropolia.fi \\ ${ }^{2}$ University of Helsinki, Helsinki, Finland \\ \{minna. lakkala, hanni.muukkonen\} @helsinki.fi
}

\begin{abstract}
The changes in software industry and software development methods call for appropriate teaching methods in academia. In addition to theoretical knowledge and coding practice, familiarity with common practices in the industry is expected from the graduates. Teamwork, collaboration and communication skills are essential demands for software engineers. These skills take years to develop, and therefore, this study presents how collaborative practices were introduced right in the beginning of information technology studies. The results of project based courses were encouraging in terms of student achievements and course completion rates. Additionally, feedback from students through an extensive survey was largely positive.
\end{abstract}

Keywords: ICT education - Collaborative practices - Professional competences · Project-based learning

\section{Introduction}

Software industry and software development practices have undergone tremendous changes in the last decades. These changes have not entered software engineering education in academia with the same force. Much of higher education still depends on very traditional teaching practices and conventional curricula. Several attempts to bring real-life engineering practices into education have been made, most notably the CDIO initiative by a number of technical universities worldwide [1] and the Aalborg Project Based Learning model [2]. Even though the theoretical backgrounds of these efforts differ, the practical implementation usually follows similar patterns on applying a project development cycle to course work, and concentrating on a problem and its solution instead of listed curriculum items (contents, skills, competences).

The Helsinki Metropolia University of Applied Sciences has a long history of undertaking curriculum changes to address a severe problem of low retention in information technology and engineering studies [3]. As long as the university funding from the government depended largely on the number of students, the motivation for implementing changes was low but when the funding scheme was changed to be based on study completions and graduations, the dilemma had to be addressed seriously three 
years ago [4]. Therefore, the university appointed a team of teachers in various disciplines to explore educational innovations in other European universities. The Aalborg model as an overall solution was chosen as the starting point for curriculum reform, which was implemented for the 2014-15 study year. The general guideline for the whole university encompassed larger study modules (5-15 ECTS credits), flexible curriculum choices as well as problem and project based learning methods.

Currently, the education at the university aims at developing the knowledge, skills, ethics, communication, and emotional component of the professional expertise to meet the need for highly integrated competence in the present day working environments. Dialogue with companies has revealed that education has failed to fully respond to the new requirements in the software industry. Demands from companies increasingly stress abilities for collaboration, efficient teamwork and professional communication. Therefore, project-based methods were included into most modules in the new curriculum. Additionally, the concepts of progressive inquiry [5] and problem-based learning were applied in course design. Moreover, participatory on-line learning environments were used to support the learner's development of understanding through collaborative construction of a shared product [6].

In information technology education, the first study year was divided into four 15 ECTS modules. Each module had a theme that introduced different major options of the studies: networks, programming and web-development, electronic devices and objectoriented programming. The project work in each module was supported by a varying amount of basic and theoretical studies such as mathematics.

The aim was to change studies in a way that makes entering the information technology profession a natural and exciting process regardless of the student background. In this paper, we discuss the results of applying working life practices immediately in the beginning of the studies.

\section{Educational Practices at Metropolia}

The studies in IT were previously loosely structured. In the old curriculum, students had 8 small courses in the fall semester that were partially studied in a large group (50 or 90 students). The incoming groups started with short courses in mathematics, physics, and the basics of information technology or media technology. Most courses were from 3 to 5 ECTS credits, and they consisted of lectures to a large audience and laboratory practice for groups of 24 students. If students failed courses, they could retake them during the following academic years. Unfortunately, this freedom and independence did not result in good retention, on the contrary: nearly $40 \%$ of students interrupted their studies already after the first year and only $40-49 \%$ graduated in 5 years (see Table 1). Interrupting studies is quite common in Finland where higher education is free. However, the high dropout rate became costly for the university, causing losses of income from the government when the funding depended on ECTS credits and graduates. 
Table 1. Retention rates at Metropolia in all engineering degree programs.

\begin{tabular}{l|l|l|l|l|l}
\hline Year & 2009 & 2010 & 2011 & 2012 & 2013 \\
\hline Retention & $42 \%$ & $40 \%$ & $43 \%$ & $45 \%$ & $49 \%$ \\
\hline
\end{tabular}

In the reform 2014, the curriculum was swapped around to include team projects and product development already in the beginning, whereas mathematics and physics were taught all along the studies. This was very different from the previous curriculum where first year was devoted mainly to basic scientific studies, languages, and other rudimentary skills. The drop-out after first year before the reform was regularly around $40 \%$, as many students could not cope with the amount of physics and electronics that was required, and they lost interest in the profession.

The majority of students in the undergraduate programmes discussed here come directly from high school or after their military service year. In August each year, about 210 Finnish students, and 50 international students who study in English begin their studies. The majority of students, around $85 \%$, are male. Currently, about a half of the students in the international group come from Vietnam, and 20\% from Nepal. Others come from various countries, especially form Eastern Europe. Their former high school studies have followed a very traditional mode of teaching, including lectures, home work and examinations [7].

Opposed to the previous organization of studies, the new curriculum was based on large 8 week modules that take full time. Each class of 25 to 30 students had one fixed classroom where they had all lessons except certain laboratory sessions that needed special equipment. The classrooms were furnished with small tables that could easily be rearranged. There were also movable white boards and connections for laptop chargers $[8,9]$.

\section{Research Methods}

The Metropolia University of Applied Sciences conducted this educational reform in a very short time and with a loose outline. Therefore, the implementations of the new curriculum were quite diverse in different departments. The follow-up of results requires collection of a big amount of data and various evaluation methods. Some of the data are presented in this study.

The outcomes of the studies were measured by several means. Most obvious measurement was the study completion rate. The statistics were gathered in four successive years, of which two represented the previous curriculum and two the new curriculum. Student and teacher views on learning of collaborative knowledge work practices were collected using a validated questionnaire.

The Collaborative Knowledge Work Practices Questionnaire (CKP) is designed for investigating students' self-reported evaluation of collaborative working practices and competence development in courses [10]. In particular, aspects of collaboration and the use of digital technology are targeted as central components in modern knowledge work. These include learning to collaborate on shared objects (e.g., reports, products, designs), iterative development through feedback, integrating individual and collaborative 
working, understanding various disciplines and practices, interdisciplinary collaboration and communication, and learning to exploit technology. The questionnaire is based on the theoretical framework of the trialogical approach on learning that emphasises collaborative knowledge creation [11].

The questionnaire was available online and had 27 statements on Likert scale plus three open questions. The 5-point statements were of the type: "During the course/study unit I have learned ... e.g. - to develop products collaboratively by using technology." The answer choices were: "Not at all (1); Just a little; Somewhat; Quite a lot; Very much (5)"'.

The questionnaire was answered by students and teachers in 13 modules of the new curriculum, including 24 teachers and 198 students who started the study in the year 2014/15. Students' and teachers' scores on the seven scales of the CKP questionnaire were compared statistically (t-test). The teachers answered the same questionnaire items with the instruction "In my opinion, students learned during the course ... e.g., to define sub-goals for the collaborative work".

Moreover, qualitative methods were included in the evaluation of the results, such as the analysis of open-ended questionnaire responses, student work results, and teacher and student interviews that help in explaining statistical results. The readiness for teamwork and other basic abilities were mainly evaluated based on classroom performance.

\section{Results}

\subsection{Retention Rates}

The initial passing rate of the 15 ECTS modules of the new curriculum was $85-100 \%$. More importantly, the retention after first year was equally high, practically all students continuing their studies in the second year [12].

The ECTS credit accumulation was investigated by examining students who stayed on track with their studies, completing the expected 30 credits in the two study periods of the first semester (Tables 2 and 3). As can be seen from the figures, the amount of students with at least 30 ECTS increased from $48 \%$ in 2013 to over $80 \%$ in the years 2014 and 2015 in the Finnish groups. The positive effect of the new curriculum model was even stronger in the international groups, where earlier completion rates were between $17 \%$ and $31 \%$ (Table 3).

Table 2. Course completions of Finnish study groups in IT (one campus)

\begin{tabular}{l|l|l|l|l}
\hline & $2012 \mathrm{n}=143$ & $2013 \mathrm{n}=149$ & $2014 \mathrm{n}=106$ & $2015 \mathrm{n}=107$ \\
\hline $1-14$ ECTS credits & $14 \%$ & $11 \%$ & $0 \%$ & $2 \%$ \\
\hline $15-29$ ECTS credits & $26 \%$ & $41 \%$ & $14 \%$ & $9 \%$ \\
\hline $30->$ & $59 \%$ & $48 \%$ & $86 \%$ & $89 \%$ \\
\hline
\end{tabular}


Table 3. Course completions of international study groups in IT

\begin{tabular}{l|l|l|c|c}
\hline & $2012 \mathrm{n}=74$ & $2013 \mathrm{n}=76$ & $2014 \mathrm{n}=45$ & $2015 \mathrm{n}=48$ \\
\hline $1-14$ ECTS credits & $23 \%$ & $14 \%$ & $0 \%$ & $2 \%$ \\
\hline 15-29 ECTS credits & $46 \%$ & $68 \%$ & $20 \%$ & $8 \%$ \\
\hline $30->$ & $31 \%$ & $17 \%$ & $80 \%$ & $90 \%$ \\
\hline
\end{tabular}

Equally, other degree programmes in engineering reveal a similar pattern. The Electrical Engineering and Automation Technology results after the first semester show that the new curriculum significantly improved results, and more than $93 \%$ of the students in these degree programmes passed all the courses in time compared to the relatively low values of $70 \%$ in 2013 and $50 \%$ in 2012 [4].

In addition to a good passing rate, course grades were also exceptionally high, especially in the international groups where the average grade was 4.0 (of 5), Table 4.

Table 4. Grade averages in international study groups in IT 2014-15

\begin{tabular}{l|l|l}
\hline Course & $\mathrm{N}$ & Average grade \\
\hline Networks A & 27 & 4.3 \\
\hline Networks B & 24 & 4.5 \\
\hline Games A & 27 & 3.5 \\
\hline Orientation A & 22 & 3.9 \\
\hline Orientation B & 26 & 3.8 \\
\hline
\end{tabular}

A comparison between international and Finnish students reveals that the international students were more ambitious and targeted at good grades, which they also achieved. The grade average in the Finnish groups in the spring term 2015 was 3.4 (of $\max .5)$.

\subsection{Questionnaire Answers}

Student and teacher opinions on the learning in the new modules were collected using the same questionnaire after each module. The responses of students and teachers from 13 modules were compared on each of the seven scales of the CKP questionnaire (Fig. 1). There were no statistical differences between the scale scores. Students and teachers gave the highest scores to learning about collaborating on shared objects (e.g., plans, designs, reports), integrating efforts in collaborative working, development through feedback, persistent efforts, and exploiting technology. Lower scores were given to understanding about various disciplines and practices as well as learning about interdisciplinary collaboration and communication. 


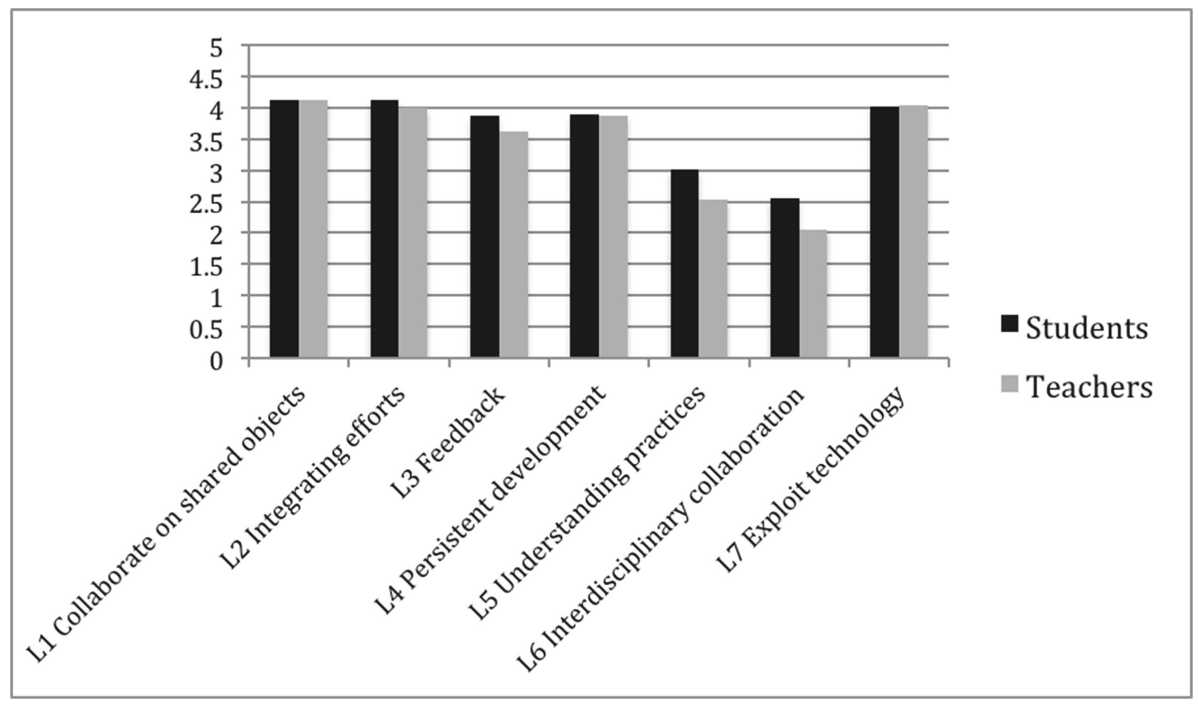

Fig. 1. Students' and teachers mean responses on the scales of the Collaborative Knowledge Practices Questionnaire. (Not at all $=1$, Very much $=5$ ).

The questionnaire contained also three open-ended questions. According to a thematic analysis, in the open-ended questionnaire responses the students addressed the following aspects as positive or impressive in the courses (233 mentions in general):

- Working methods (90): Practical tasks (24), Group work (30), Learning community and atmosphere (17), Working methods in general (11), Project work (4), Freedom of choice (4);

- Teaching and guidance (52): Good teachers and teaching (36), Teachers' positive attitude (7), Guidance and feedback from teachers (9);

- Content (31): Interesting and useful content (31);

- Outcomes (28): Learnt new things (21), High-quality products (7);

- Organization (28): Good entity (15), Appropriate phase of work (7), Good integration of subjects (6);

- Facilities (4): Good study premises and equipment (4).

The negative aspects were partially the same, or sometimes the other side of the coin (180 mentions in general):

- Organization (70): Tight timetable and heavy workload (24), Uneven workload (13), Confusing and incomplete arrangements (12), Poor integration of subjects (12), Poor communication practices (9);

- Working methods (60): Problems in group work (18), Too little teaching of theory (13), Challenging working methods (10), Restless classroom (5), Too much group work (7), Too much teaching of theory (4), Compulsory attendance (3);

- Content (42): Difficult content (29), Not interesting or useful content (13); 
- Teaching and guidance (27): Poor teachers and teaching (13), Too little guidance and feedback (6), Unclear goals and evaluation criteria (8);

- Facilities (8): Poor study premises and equipment (8).

As was noted before the arrangements of the modules were varied, therefore some aspects such as amount of theory or guidance could be very different between modules.

\subsection{Adoption of Teamwork}

According to student interviews in the classroom, none of the international students had previous experience in teamwork or team projects. However, the transition to university studies seemed to make the students open to a new way of learning, and all approached the teamwork mode positively. As contrasted to students who had previous university studies particularly in Finland, they adapted quickly to self-directed project work. Only students who had started university studies elsewhere and transferred to our university, found the new mode difficult. Many of them had problems in adapting to regular attendance and shared responsibility of teamwork. Interestingly, even one year of previous studies had fixed their study habits.

Teamwork and project work were more challenging to assess fairly than individual deliverables. Teams of six or seven students were problematic in this respect but unfortunately the lack of equipment forced to do some projects in such large teams. Most projects were executed in teams of four. Instructors tried to avoid unfair situations by choosing half of the deliverables as individual assignments (such as mathematics, programming exams and student home pages). Moreover, the continuous presence of teachers in the classroom gave them an understanding of each student's skills. At the end of some projects, students were requested to indicate how much each team member contributed to the project. In most cases, students gave a fair assessment of each other and even downplayed their own part.

As teamwork is not completely new in the curriculum, the results can also be compared with earlier experience. Numerous reports show that project work has always had several benefits such as better course completion and student satisfaction $[13,14]$. On the other hand, it had no discernible overall impact on retention and graduation when it was only a small part of the curriculum.

The orientating courses of the first year enabled students to acquire basic knowledge of the study environment together. The collaborative practices developed during the first courses could later be observed when the students proceeded with their studies. How well the teamwork and collaboration skills persisted during the second academic year, was monitored and the results varied depending on the arrangements in the subsequent modules. When courses were built on collaboration the effect was positive, but when they followed traditional learning patterns, the students also reverted to those.

\section{Discussion and Conclusion}

The new study modules were by no means similar to each other. Much of the realization depended on the teacher team, some of whom preferred to divide the module into smaller 
parts among each other. All modules except one had a larger project, though. From the students' point of view, having a permanent home class was a significant difference to earlier years. Arguably, belonging to a group could have been a decisive factor in student retention. Despite the fact that the students were split to new groups according to the major subject selection the second year, where only part of the former classmates followed, they already had a network of study mates.

As the curriculum contents also changed in the reform, the results can be challenged in claiming that the students passed because of low requirements. However, the teachers involved would not agree, as actually the workload and requirements were set high. On the other hand, the number of individual deliverables within courses was certainly lower than before, which made the management of studies easier than before. Peer pressure within teams presumably added to the amount of work that was actually done because individuals were denied the privilege of procrastination. In particular students who had weaker self-regulation skills benefitted from a well-organized study mode. They had no choices to make in the first year, and the schedule for a week was always nearly similar.

According to the survey results, the teachers' and students' responses to the scales evaluating students' learning of knowledge work competences during the study modules were aligned. The average scores were quite high except the two scales that measured understanding practices and knowledge of various disciplines and interdisciplinary collaboration, which were not emphasized in the first-year studies. Open-ended responses revealed that students valued especially the working methods as well as teaching and guidance. They found disturbing particularly the organization of working, which might reflect the novelty of the implementation of teaching in larger modules together with a team of teachers. Also, various working methods were mentioned by students as unsatisfactory, including challenges in group work. However, it is encouraging that there were, in all, clearly more mentions about positive than negative aspects of the study experiences.

The main aims of the reform such as improved retention rate and high rate of completed study modules were achieved in an impressive manner. Despite the great variation of methods in course organization and teaching, the collaborative mode of learning and teaching seemed to contribute to a successful beginning of studies, and in particular to student enthusiasm and goals. Additionally, there were some indications that students adopted collaborative working practices that are expected by the software industry. Further research could address teachers' team teaching and the variation of course designs, their execution and related learning outcomes. Further, how students continue in their study programs is of interest to see; whether the reorganization of the first year of studies has continuous effects in terms of retention, or the completion of study credits. Further research could document the development of collaboration skills and other working life competences and aim to follow the students through their future transition to industry.

Acknowledgments. The study was partially supported by the Lifelong Learning Programme of the European Union under Grant KA3MP-2013-4764/001-001 (Promoting Knowledge Work Practices in Education; the KNORK project; http://knork.info). 


\section{References}

1. Crawley, E.F., Malmqvist, J., Östlund, S., Brodeur, D.R.: Rethinking Engineering Education: The CDIO Approach. Springer, New York (2007)

2. Dalsgaard, F., Du, X., Kolmos, A.: Innovative application of a new PBL model to interdisciplinary and intercultural projects. Int. J. Electr. Eng. Educ. 47, 174-188 (2010)

3. Schrey-Niemenmaa, K., Karhu, M., Ristola, A., Sirkjärvi, J.: The metropolia adaptation of CDIO in all 20 of its engineering study programmes. In: Proceedings of the 6th International CDIO Conference, École Polytechnique, Montréal, 15-18 June 2010

4. Valmu, H., Vartia, R., Kupila, E., Heikkinen, T.: Significantly improved student progression results by means of course integration and collaborative pedagogy in the degree programmes of electronics, electrical engineering and automation technology of the Helsinki Metropolia UAS. In: Proceedings of 19th International Conference on Engineering Education, ICEE 2015, pp. 32-40 (2015)

5. Muukkonen, H., Lakkala, M.: Exploring metaskills of knowledge-creating inquiry in higher education. Int. J. Comput.-Support. Collaborative Learn. 4(2), 187-211 (2009)

6. Paavola, S., Hakkarainen, K.: Trialogical approach for knowledge creation. In: Tan, S.C., So, H.J., Yeo, J. (eds.) Knowledge Creation in Education, pp. 53-73. Springer, Singapore (2012)

7. Holvikivi, J.: From theory to practice: adapting the engineering approach. In: Proceedings of International Conference on Engineering Education, Turku (2012)

8. Hjort, P., Holvikivi, J., Vesikivi, P., Lukkarinen, S.: Student collaboration and independence from day one in higher education. In: Proceedings of the 43rd Annual SEFI Conference, Orléans, France (2015)

9. Lukkarinen, S., Holvikivi, J., Hjort, P., Mäkelä, M., Lakkala, M.: Creation of a collaborative study community in engineering studies. In: Proceedings of 19th International Conference on Engineering Education, ICEE 2015, Zagreb, Croatia, pp. 597-603 (2015)

10. Muukkonen, H., Lakkala, M., Toom, A., Ilomäki, L.: Assessment of competencies in knowledge work and object-bound collaboration during higher education courses. In: Kyndt, E., Donche, V., Trigwell, K., Lindblom-Ylänne, S. (eds.) Higher Education Transitions: Theory and Research. EARLI. New Perspectives on Learning and Instruction (2016)

11. Paavola, S., Lakkala, M., Muukkonen, H., Kosonen, K., Karlgren, K.: Trialogical learning: The roles and uses of design principles in a project on trialogical learning. Res. Learn. Technol. 19(3), 233-246 (2011)

12. Vesikivi, P., Hjort, P., Lakkala, M., Holvikivi, J., Lukkarinen, S.: Adoption of a new projectbased learning (PBL) curriculum in information technology. In: Proceedings of the 43rd Annual SEFI Conference, Orléans, France (2015)

13. Markkanen, H., Holi, M., Benmergui, L., Bauters, M., Richter, C.: The knowledge practices environment: a virtual environment for collaborative knowledge creation and work around shared artefacts. In: EdMedia: World Conference on Educational Media and Technology, Vienna, Austria (2008)

14. Muukkonen, H., Kosonen, K., Marttiin, P., Vesikivi, P., Kaistinen, J., Nyman, G.: Pedagogical design for knowledge creating inquiry in customer projects. Knowl. Manage. E-Learn. 5(3), $278(2013)$ 